\title{
Luís de Lima em Portugal antes do 25 de Abril
}

\author{
MÁRCIA REGINA RODRIGUES
}

Luís de Lima (1925-2002), among several pioneer achievements, was one of the first directors to stage the work of Eugène lonesco in Brazil and Portugal, playing a fundamental role in the development of theater in the two countries in the second half of the twentieth century. The present text describes and analyzes the theatrical trajectory of Luís de Lima in Portugal before April $25^{\text {th }}$, after the presentation of the lonesco Festival in Lisbon in 1959, and of the presentations that he directed in the theater groups of Porto (1959-1960), Coimbra (1961-1962, 1969) and Lisbon (1967), considering in particular his proposals for staging and the context of theatrical production of the period. The goal is to emphasize the importance of the artist's contributions to the history of Portuguese theater at a time when the dramatic art produced in the country sought scenic renewal and faced the impediments of censorship.

LUÍS DE LIMA / PORTUGUESE THEATER / THEATER OF THE TWENTIETH CENTURY / THEATER GROUPS

1.

As diversificadas realizações de Luís de Lima não o caracterizam como temperamento dispersivo. Ao contrário, todas se somam, se imbricam, formando uma personalidade multifacetada, de evidente riqueza.

$O$ artista se desdobra em várias especialidades, apoia-se no intelectual rigoroso, distante do improvisador despreparado.

SÁBATO MAGALDI

Conhecido por ter sido o responsável pela «primeira divulgação de Ionesco e do teatro do absurdo nos palcos brasileiros» (Magaldi, 2003: 258) e também na cena portuguesa, o ator, mímico, encenador, professor, produtor e tradutor Luís de Lima (1925-2002) teve um papel importante no teatro produzido no Brasil e em Portugal na segunda metade do século $\mathrm{Xx}$. 
Luís de Lima iniciou a sua formação teatral no Conservatório Nacional de Teatro de Lisboa e, no final dos anos 40, partiu para Paris, onde obteve uma bolsa do governo francês para complementar os seus estudos no Conservatório Nacional de Arte Dramática e na Escola de Mímica Étienne Decroux. Como mímico, ele integrou a companhia de Marcel Marceau e participou de turnês pelos EUA, Europa e África. Em 1953, trocou Paris por São Paulo quando foi convidado por Sábato Magaldi ${ }^{1}$ para ministrar aulas de interpretação na Escola de Arte Dramática (EAD) - na altura um «dos principais pontos de apoio para o desenvolvimento do moderno teatro brasileiro» (Silva, 1989: 16) - e acabou permanecendo no Brasil, mas viajando sempre ao seu país de origem para a realização de várias atividades teatrais.

Assim, por pelo menos uma década, entre 1959 e 1969, Lima esteve a trabalhar entre Brasil e Portugal. Além de traduzir, encenar e divulgar a obra de Ionesco nos dois países, também traduziu, adaptou e levou à cena peças de Jean Tardieu, Arthur Adamov, Samuel Beckett, Arthur Miller, Robert Thomas, dentre outros, atuando como ator em grande parte dos espetáculos. Depois da experiência na Escola de Arte Dramática de São Paulo, ele dirigiu coletivos teatrais no Porto, Coimbra e Lisboa num período em que os grupos universitários e os de teatro experimental representavam de fato a possibilidade de renovação cênica necessária para que o teatro português conseguisse sair do atraso a que estava condicionado, em grande parte pelos impedimentos da censura imposta pelo regime político vigente. No contexto da crise acadêmica dos anos 6o, Luís de Lima foi expulso de Portugal (1962 e 1969) pela ditadura salazarista, voltando ao país em 1974 para dirigir, no Teatro Villaret, Liberdade, Liberdade (1965), de Flávio Rangel e Millôr Fernandes, adaptando a peça - em parceria com Luiz Francisco Rebello e Hélder Costa ao contexto da democracia conquistada pela Revolução dos Cravos.

O presente texto descreve e analisa a trajetória teatral de Luís de Lima em Portugal antes do 25 de Abril, a partir do seu retorno ao país para a apresentação do Festival Ionesco, em 1959, passando pelos espetáculos que ele dirigiu nos grupos de teatro do Porto (1959-1960), Coimbra (1961-1962, 1969) e Lisboa (1967), considerando nomeadamente as suas propostas de encenação e o contexto de produção teatral

De acordo com Sábato Magaldi, uma comissão de três membros - o próprio Magaldi, Jean Vilar (diretor do Teatro Nacional Popular francês) e o crítico, dramaturgo e filósofo Gabriel Marcel ficou encarregada de escolher um professor de interpretação para a EAD. Dentre vários nomes, foi escolhido o de Luís de Lima, «que a par do talento artístico, tinha a virtude de falar português, simplificando o problema de comunicação com os alunos» (Magaldi, 2003: 258). 
do período. O objetivo é enfatizar a importância dos contributos de Lima para a história do teatro português numa altura em que a arte dramática produzida no país buscava pela renovação cênica e sofria os impedimentos da censura.

A atual geração parece encontrar no teatro o melhor e mais eficaz meio de expressão dos seus anseios. Estuda, pratica e discute todos os problemas relacionados com a arte teatral.

LUÍS DE LIMA

O sucesso do premiado Festival Ionesco no Brasil2, sob a direção de Luís de Lima, possibilitou a digressão do espetáculo a Portugal. Além de $A$ lição e A cantora careca, peças que faziam parte da montagem brasileira do Festival, Lima acrescentou As cadeiras ao espetáculo apresentado em Lisboa, em 1959, «ao embasbacado público de então», como escreveu Arthur Ramos (1968: 70). O Festival Ionesco deu notoriedade a Luís de Lima, que era pouco ou nada conhecido: «É português, sabêmo-lo todos, e isso conta também na satisfação com que o vimos, modesto, talentoso e honesto, triunfar entre nós» (Jacinto, 1959: 452).

Logo depois da temporada do Festival Ionesco, e após uma rápida viagem a Paris, Luís de Lima passa a trabalhar entre Brasil e Portugal. Ainda no ano de 1959, ele assume a direção artística do recém-formado Grupo de Teatro Moderno do Clube Fenianos Portuense, o GTM, e, em parceria com Alexandre O'Neill, traduz e adapta Ubu Rei para ser encenada pelo coletivo. A peça de Alfred Jarry - intitulada Mestre Ubu na tradução - cabia perfeitamente nos objetivos do conjunto, que se denominava Grupo de Teatro Moderno, mas foi proibida a apresentação pela censura e o GTM acabou por eleger um clássico da dramaturgia: Arlequim, servidor de dois amos, de Carlo Goldoni, com tradução e direção de Luís de Lima, que também fez o papel principal. Houve quem criticasse a legitimidade da escolha da peça de Goldoni por um grupo que se intitulava Teatro Moderno; porém, Carlos Porto surgiu com a seguinte justificativa: «pela minha parte, parece-me que essa dúvida não tem razão de ser. 
O teatro é moderno não pelo texto que apresenta, mas pelos processos cénicos com que esse texto é encenado» (Porto, 1973: 190-191).

Arlequim estreou em março de 1960 no Teatro Sá da Bandeira e integrou o II Ciclo de Teatro, organizado pelo Ciclo de Iniciação Teatral da Academia de Coimbra (CITAC). O jovem ator Mário Jacques, que se destacou no papel do Pantaleão, foi a grande «revelação do espectáculo» (Porto, 1997: 190) e, alguns anos mais tarde, em depoimento a Artur Ramos, ele fez a seguinte afirmação a respeito do diretor do GTM: «Luís de Lima era extraordinariamente dinâmico: o nosso grupo, constituído por amadores, trabalhava todos os dias da semana, fascinados pelo interesse daqueles ensaios» (Ramos, 1968: 70).

O GTM estreou com «o pé direito de um grupo a sério com um plano consciente e válido» (Vilaça, 1960:229) e o espetáculo obteve boa recepção da crítica; porém, as tensões com a censura salazarista resultaram no encerramento precoce de todas as atividades da recém-formada companhia teatral. De acordo com Carlos Porto, o GTM «foi apresentar o espectáculo [Arlequim] a Viana do Castelo, e uma hora antes da hora marcada, com o Teatro Sá da Miranda cheio, aquele foi proibido, acto arbitrário e incompreensível que levou o grupo a apresentar-se num bar da cidade» (Porto, 1997: 118); sobre o mesmo episódio, Alexandre Babo conta que «Luís de Lima tinha estado ausente há muito do país e custava-lhe a crer que, numa terra minimamente civilizada, sem ser uma república das bananas, pudesse cometer-se tal atropelo» (Babo, 1993: 308). O fato é que o promissor GTM desfez-se, tendo realizado somente um único espetáculo.

Apesar da censura, a receptividade positiva do público de Arlequim, servidor de dois amos chamou «a atenção sobre Luís de Lima, que surgia como alguém que sabia conciliar o rigor da técnica ao prazer lúdico da redescoberta dos clássicos» (Barata, 2009:182). Essa característica-aliada ao grande empenho de Lima quanto ao refinamento da expressão corporal na direção do ator - marca as suas atividades de encenador em solo português e, em seguida, é convidado a assumir a direção do CITAC.

No início da década de 1960, a nova direção do CITAC objetivava não só assimilar as tendências estéticas já praticadas em outros países como promover a renovação e a atualização do repertório de espetáculos a partir da encenação de peças da dramaturgia moderna e contemporânea, de autores estrangeiros e também portugueses. No curso de teatro do CITAC, Luís de Lima se dedicou à formação dos atores, transmitindo aos integrantes do grupo «algumas das técnicas com que contactara e 
que assinalavam uma ruptura com a tradição declamatória de certo teatro» (idem, 93), pondo em prática os exercícios de técnicas vocais e de expressão corporal, muitas delas já trabalhadas na EAD de São Paulo e no GTM do Porto.

A peça escolhida foi $A$ descoberta do novo mundo, de Morvan Lebesque, que Luís de Lima havia traduzido, em parceria com Gilda de Melo e Sousa, e adaptada para a montagem que realizara na EAD. O CITAC submeteu essa peça à comissão de censura para obtenção da licença de representação e ela foi aprovada, mas com cortes. Talvez por essa razão, ou por questões de ordem prática, Luís de Lima acabou mudando de ideia e optou por peças em um ato para o primeiro espetáculo que dirigiu, em 1961, no CITAC: Conversação Sinfonieta, de Jean Tardieu; O professor Taranne, de Arthur Adamov, e A rabeca, do estreante dramaturgo português Hélder Prista Monteiro. Tal decisão não só facilitava o trabalho de encenação e montagem, dada pela brevidade dos textos, como promovia a reunião, em um mesmo espetáculo ${ }^{3}$, de autores da dramaturgia contemporânea e, ao mesmo tempo, valorizava a dramaturgia nacional que, então, nascia. Tudo isso propiciava ao CITAC, que se relançava sob nova direção, alcançar a «maioridade estética» (idem, 186), e o grupo tornou-se uma referência de teatro universitário.

Depois da montagem de peças contemporâneas, e embora primasse por um repertório teatral moderno, a direção do CITAC escolheu o Tartufo, de Molière, com tradução brasileira de Guilherme Figueiredo, para o ano seguinte. O Tartufo estreou em 5 de abril de 1962, no IV Ciclo de Teatro do CITAC, com cenário e figurinos do francês André Acquart. ${ }^{4}$ Luís de Lima propunha uma «leitura actualizada do texto clássico servindo-se do rigor interpretativo e da grande metáfora cénica que Acquart criara. Era o confronto com a prática arqueológica em que muitos ainda se mantinham» (idem, 187); essa novidade atraiu o público, e o espetáculo manteve o Teatro Avenida com lotação esgotada.

Enquanto esteve no CITAC, Luís de Lima também montou espetáculos-solo - Acto sem palavras II e A última gravação, de Samuel Beckett -, de modo que o trabalho corria a contento; contudo, no contexto da crise acadêmica de 1962, Lima foi expulso de Portugal pela

3 O espetáculo de peças em um ato foi apresentado no III Ciclo de Teatro de Coimbra (de 27 de fevereiro a 24 de abril de 1961), organizado pelo CITAC, com a colaboração da Associação Académica de Coimbra e subsidiado pela Fundação Calouste Gulbenkian.

4 André Acquart (1922-2016), importante cenógrafo francês dos espetáculos de Roger Blin e Jean-Marie Serreau, dentre outros. 
ditadura salazarista. De volta ao Brasil, ele acompanhava as atividades teatrais dos seus colegas portugueses e mantinha contatos; assim, depois de alguns anos, em 1967, ele volta a Portugal para trabalhar mais uma vez com um grupo universitário de teatro, desta feita com o Cénico da Faculdade de Direito da Universidade de Lisboa.

Ao chegar a Lisboa para dirigir o Cénico, Luís de Lima encontra um grupo experiente que correspondia à sua proposta de trabalho dinâmico e de realização de uma montagem teatral em curto espaço de tempo. A peça escolhida para ser montada com o Cênico foi Mestre Gil-dramaturgia do próprio Lima em parceria com Domingos Mascarenhas, já encenada no Brasil, com o título de Mestre Gil Quinhentão, por ocasião das Comemorações Vicentinas e do IV Centenário do Rio de Janeiro, em 1965.

O Cénico de Direito «teve apenas cerca de um mês para preparar o espectáculo» (Lima, 1967: 15), sendo que alguns componentes do grupo jamais tinham participado num espectáculo de teatro..$^{5}$ Como refere o programa da peça, o espetáculo consistia numa «acção teatral baseada em textos de Gil Vicente, Martins Pena, Ariano Suassuna e Bertolt Brecht» (programa do espectáculo, 1967); portanto, era uma experiência dramatúrgica realizada a partir da colagem de textos, método bastante considerado por Luís de Lima: «[a] colagem permite usar bons textos, mas apenas estão ali, são os elos de uma cadeia com que pretendo ilustrar alguma ideia» (Lima, 2003: 42).

Na apropriação de diálogos de diferentes peças, a inserção de Brecht merece atenção num momento em que a obra teatral do dramaturgo alemão estava impedida pela censura de ser encenada em Portugal; apesar disso, Mestre Gil conseguiu a licença de representação. O roteiro de Lima e Mascarenhas enfatiza a figura do juiz Azdak - personagem de $O$ círculo de giz caucasiano - e coloca a ideia de que «peças de Brecht como esta são autênticos autos, como os vicentinos...» (Lima/Mascarenhas, 1967: 46). Afirma que «já tem sido salientada, aliás, a identidade de concepção do espetáculo teatral, que se nota em Brecht e em Gil Vicente... Neste caso a analogia é sublinhada pelo parentesco que liga o Juiz da Beira ao Juiz Azdak do Círculo de giz caucasiano» (ibidem).

No que se refere à escolha estética, Mestre Gil se estrutura na linha do teatro épico-brechtiano ao apresentar comentários e explicações dirigidas diretamente ao público, interrompendo a cena representada, e se alinha 
à encenação moderna com a atualização de textos considerados clássicos. Quanto às peças vicentinas especificamente, Luís de Lima explica que havia atualizado certas palavras «para dar maior rendimento, mas, no entanto, sem tirar o sabor quinhentista ao conjunto» (Lima, 1967: 15); de modo que procurou manter alguma fidelidade à obra de Gil Vicente, o que lhe assegurava afirmar, em depoimento dado à imprensa, que se pudesse levar o espetáculo a Coimbra «dedicá-lo-ia ao Prof. Paulo Quintela», e ainda que, «se Gil Vicente [estava] vivo, isso [era] obra de Paulo Quintela» (apud Vasconcelos, 1967: 8), num reconhecimento necessário do trabalho de divulgação e pesquisa acerca do teatro de Gil Vicente levado a cabo pelo professor da Faculdade de Letras e diretor artístico do TEUC. Apenas alguns dias depois das duas apresentações no Teatro Villaret, o Cénico de Direito apresentava Mestre Gil no importante Festival Mundial de Teatro Universitário em Nancy, coroando o êxito do espetáculo.

Além de ter «[mostrado] uma forma inovadora de fazer Gil Vicente» (Barata, 2009: 226), Luís de Lima efetivou o aperfeiçoamento da técnica de atuação, atribuindo «ao trabalho de actor uma importância detectável nos pequenos pormenores» (ibidem), o que mostra que ele realizava um aprofundamento das práticas de interpretação junto aos elementos dos grupos que dirigia.

Terminado o trabalho no Cénico, Lima parte novamente para o Brasil, desta vez por vontade própria, retornando a Portugal dois anos mais tarde para dirigir o Teatro dos Estudantes da Universidade de Coimbra, o TEUC, cujo diretor, Paulo Quintela, por divergências internas, acabara por se demitir quando o grupo estava às vésperas de completar trinta anos de existência.

Luís de Lima chega a Coimbra exatamente com o que esperavam dele: um texto clássico - $A$ ilha dos escravos, de Marivaux - assentado numa proposta de encenação atual e, como não poderia deixar de ser, era a primeira vez que a peça seria encenada no país. Em pouco tempo, o experiente diretor levantou o espetáculo, com os estudantes entusiasmados com o processo de montagem que trazia renovação ao TEUC, e $A$ ilha dos escravos satisfez os propósitos esperados: chamou a atenção do público e da crítica, e no palco «estivera um clássico servido por uma actualização que, embora em alguns momentos tocasse a empatia fácil, demonstrava o abandono da intocabilidade reconstitutiva do texto» (idem, 140). Assim, Lima mais uma vez comprovava a viabilidade de se encenar uma peça clássica liberta de formas cênicas ultrapassadas. 
$\mathrm{Na}$ adaptação cênica, uma das marcas de atualização da peça de Marivaux, realizada por Lima, foi a inserção de um prólogo, de autoria de Almeida Faria, escrito em quadras, constituindo um total de sessenta e quatro versos; esse «Texto de apresentação» é dirigido diretamente ao público com a função de contextualizar a peça - «A obra já é antiga/ tem mais de 200 anos/ embora trate de escravos/ é dedicada a seus amos» (Faria, 1969: 1) - e apresentar as personagens - «Quanto às minhas marionetes/ que vedes aqui tão vivas/ são Okassis e Cleanta/ Arlequim e Eufrosina» (idem, 2) -, chamando a atenção do público no final com os seguintes versos: «Senhoras e meus senhores/ desejo apenas dizer-vos/ olhai bem para este palco/ porque neles haveis de ver-vos» (idem, 3).

A atualização de $A$ ilha dos escravos na encenação de Luís de Lima era o que mais chamava a atenção da crítica, que, de alguma forma, esforçava-se em comentar os métodos do encenador. José Tavares Pinto, em artigo da revista Vértice, comentava o trabalho de Luís de Lima, a atualização do texto da peça (apud Pinto, 1969: 404-405) e registrava uma descrição precisa do espetáculo:

Feição que é visível: 1 - na marcação (frontal, condicionada pela presença do público e não apenas por estímulos do texto e, portanto, a não explorar conscientemente a profundidade do palco), 2 - no uso constante de uma linguagem mímica (gesto independente em vez de complementar a palavra), 3 - na criação de situações que ultrapassam o guião dramático (e este é o aspecto histórico mais saliente de tal tipo de teatro - a criação que transcende o campo acanhado do texto). Daí partiu Luís de Lima para a actualização da obra, dando-Ihe um sentido novo sem lhe retirar os fundamentos verbais (mau grado a tradução excessivamente livre), antes reduzindo-os a parte dum todo. O que, logo à primeira vista, ressalta não só da criação do prólogo e do final, mas também da transformação parcial e intencional das personagens em marionetes. Uma habilidade que constitui em salientar o ridículo e o anacronismo de certas passagens do texto e em modificar o sentido dessas passagens, lançando mão da tradicional irreverência de fala que se concede ao Arlequim. (Pinto, 1969: 405)

Ainda sobre a questão da atualização de texto clássico, Carlos Gil publicou em A Capital uma série de depoimentos sobre o tema, recolhidos dos encenadores Fernando Gusmão, Ricard Salvat, Adolfo Gutkin e Luís de Lima. Luís de Lima falou sobre a «actualização através da forma» 
e observou que «compete ao encenador revitalizá-la na sua parte cênica, pondo em jogo o máximo de recursos expressivos e técnicos com que actualmente conta o teatro moderno» (apud Gil, 1969: 5). Uma explicação mais clara sobre as intenções da atualização da peça de Marivaux aparece num texto policopiado, assinado por Luís de Lima ${ }^{6}$ :

A Ilha dos Escravos é, no original francês, uma obra ambígua que pretende denunciar, através do tom da comédia alegórica, a desigualdade entre os homens. A llha dos Escravos passa a ser na tradução livre portuguesa uma obra directa que pretende denunciar, através do tom da comédia burlesca, a desigualdade que os homens permitem que reine entre eles. A Marivaux não interessava ir até o fim da denúncia. A nós interessa. Daí o tentarmos mostrar quanto são lamentáveis, como realidades sociais, tanto os patrões quanto os escravos. Se a peça é apresentada - com texto da nossa invenção - como se fosse um espectáculo de marionetes, é para melhor fazer chegar ao entendimento geral que, se não nos libertarmos das regras velhas, continuaremos todos a ser marionetes manobradas pelos donos das ditas. (Lima, 1969: s/p)

O tom de denúncia e protesto é evidente, marcado por um ensinamento presente tanto no texto propriamente dito como pelo recurso cênico utilizado, como observa Oliveira Barata:

[Actores] marionetas tinham sido introduzidos por um feirante que, em forma de prólogo, dizia um texto que Luís de Lima solicitara a Almeida Faria. O espectáculo terminava precisamente com a apresentação de quatro enormes titereiros que representavam o poder económico, o militar, o religioso e o judicial. (Barata, 2009: 140)

O espetáculo do TEUC parece ter provocado a inevitável comparação da situação apresentada na peça com a realidade concreta de Portugal. Assim, a escolha de $A$ ilha dos escravos parecia atender a duas demandas simultaneamente: a de estímulo a um grupo de teatro que precisava se libertar das velhas regras de interpretação, o que se encaixava naquele momento no TEUC, e a de conscientização do público em geral acerca da situação política e social do país. 
Como se sabe, no final da década de 1960, Portugal vivia o mais intenso movimento de oposição à ditadura vigente, oposição apoiada com vigor pelos estudantes desde a crise acadêmica de 1962, reacendida a partir do Maio de 1968 francês, e que geraria nova crise nas universidades naquele mesmo ano de estreia da peça, 1969, culminando na expulsão de Luís de Lima do país e, pouco mais tarde, na proibição da representação nos palcos de $A$ ilha dos escravos, que de início havia sido aprovada pela censura para maiores de dezessete anos.

Como relata Oliveira Barata, Luís de Lima foi expulso de Portugal na mesma altura que Ricard Salvat, encenador do CITAC (idem, 141); já o diretor do TEUC foi levado por dois agentes da PIDE e obrigado a viajar de volta ao Brasil, de onde depois telefonou e pediu «com indisfarçável comoção» que o grupo continuasse a encenar $A$ ilha dos escravos (ibidem).

No caso do teatro universitário, apenas os textos das peças a serem encenadas deveriam passar pelo crivo da comissão de censura, não os espetáculos; porém, isso muda e o TEUC, bem como os demais grupos, confirma que o cerco da repressão estava se fechando em torno deles. Mesmo com a expulsão de Luís de Lima pela PIDE, o TEUC pretendia continuar a temporada de apresentações da peça e manifesta repúdio às novas determinações da censura, como se pode verificar na «Carta Aberta» do TEUC, datada de 27 de junho de 1969:

Julgavam talvez as autoridades que o nosso ânimo e vontade esmoreciam com a expulsão de Luís de Lima. Mas enganaram-se: quando a vontade é colectiva não se mata com tanta facilidade [...]. Logo após a expulsão do nosso encenador recebemos uma carta da Censura informando-nos de que todo e qualquer espectáculo devia ser visado, para além da habitual e rigorosa (mas não escrupulosa!) censura de texto, com uma outra censura, esta ao próprio espectáculo no respectivo «ensaio de apuro», cuja data deverá ser comunicada à Direcção desses serviços «com pelo menos cinco dias de antecedência». Não havia para os grupos de Coimbra tal precedente de censura prévia ao espectáculo. Assim, como facilmente se compreenderá, poderão os «inquisidores», com um não de momento, deitar por terra um trabalho que custou tempo, dinheiro e o melhor esforço de quem nele participa. Em posterior entrevista com o MEN [Ministério da Educação Nacional] fez a Direcção do TEUC sentir o seu papel de desacordo com essa medida, e, como habitualmente, o assunto ficou para estudo, naquela meditação de gabinete a que também já todos nos habituámos. (TEUC, 1969: 2) 
O TEUC havia apresentado A ilha dos escravos no IX Ciclo de Teatro, organizado pelo CITAC, e realizado uma digressão pelo país até a peça ser proibida quando os seus intérpretes se preparavam para apresentá-la no Porto (apud Barata, 2009: 141), sendo o grupo obrigado a findar de vez o projeto iniciado por Luís de Lima.

Luís de Lima só voltaria a trabalhar no teatro em Portugal depois do 25 de Abril, com o mesmo entusiasmo de todos aqueles que queriam participar do processo de democratização do país.

A arte e a cultura são meios maravilhosos para suprimir as distâncias que separam as nações: são forças poderosas que estreitam os povos no amplexo espiritual da civilização.

LUÍS DE LIMA

O percurso teatral de Luís de Lima em Portugal esteve marcado pelas experiências que ele realizara no Brasil, nomeadamente a montagem de peças, as quais eram muitas vezes retrabalhadas nos grupos de teatro como exercícios de palco ou efetivamente levadas à cena, como aconteceu com Mestre Gil (Brasil, 1965; Portugal, 1967), alcançando com isso um aprimoramento da técnica teatral.

Assim, no período de 1959 a 1969, as atividades que Lima havia realizado no Brasil foram praticamente a «base», digamos, de todo o seu trabalho de experimentação teatral no que diz respeito à atuação, encenação e tradução, motivando-o a repetir a experiência em Portugal como, por exemplo, a encenação das peças de Ionesco. Foi na EAD de São Paulo que ele desenvolveu a sua vocação de professor teatral e experimentou novas técnicas de cena com os seus alunos de interpretação, práticas que ele repetiu junto aos grupos de teatro do Porto, Coimbra e Lisboa.

Além das atividades realizadas junto aos grupos de teatro, Luís de Lima não se cansou de divulgar o que se desenvolvia nos palcos brasileiros, especialmente no circuito São Paulo-Rio de Janeiro, dando a conhecer em Portugal os atores, dramaturgos e encenadores brasileiros tanto nas aulas de teatro quanto nas palestras proferidas ou nas entrevistas por ele concedidas em solo português.

Nos dois países, em que o teatro era muitas vezes diminuído em relação ao que se fazia no resto do mundo, Luís de Lima não se deixava 
contaminar por nenhum complexo de inferioridade, confiava na sua formação e experiência e, interessado pelo teatro que se produzia na França, onde vivera, e nos Estados Unidos, buscava novas peças e colhia informações teatrais, surgindo daí as suas traduções. Traduzia o texto essencialmente para o palco, numa boa afinação linguística, muitas vezes optando pelos modos de falar do brasileiro. Tal trabalho de elaboração linguística se dava também com a dramaturgia clássica, que passava sempre por um processo de atualização do texto para as montagens que realizava. Assim, com o afã de renovar o repertório cênico - fosse pela encenação do que de mais atual se fazia no teatro do mundo ocidental, fosse pela atualização de peças do teatro clássico -, Luís de Lima escolhia muitas vezes obras de autores estrangeiros, o que não quer dizer que desprezasse os dramaturgos de língua portuguesa, pois levou à cena pela primeira vez uma peça do então estreante dramaturgo Hélder Prista Monteiro.

Cumpre lembrar que Luís de Lima, na prática teatral que desenvolveu, aproveitou todo o repertório e bagagem adquiridos nas viagens que fizera, e sem se desvincular por completo da terra natal, voltava sempre a Portugal para pequenas ou médias temporadas, trabalhando arduamente para a desejosa renovação do teatro português, que, devido em grande parte aos impedimentos censórios da ditadura salazarista, vivia o maior dos atrasos.

Em Portugal, e também no Brasil, Luís de Lima participou ativamente no movimento de renovação da cena. Tendo chegado ao Brasil num momento do auge cultural que foi o dos anos 50, fez parte do movimento do moderno teatro, especialmente com a tradução e a encenação de peças ainda não levadas ao palco, contribuindo assim para a atualização do repertório da cena brasileira. Em Portugal, sem ficar por muito tempo afastado do Brasil, Luís de Lima foi praticamente um militante do teatro universitário, que - diferentemente de qualquer amadorismo que se possa atribuir a esse tipo de teatro - foi à época um dos caminhos possíveis para o desenvolvimento teatral no país, que estava sob o poder da já longeva ditadura. Assim, driblando a censura, Luís de Lima fez o que de melhor se faz contra um regime ditatorial: contribuiu para a formação de jovens universitários, tendo muitos deles seguido a carreira teatral e fazendo do teatro as armas da resistência.

Luís de Lima - «sempre guiado pelo espírito de liberdade, pela seriedade e dignidade profissional» (Lima, 2003: 61), como ele próprio afirmou numa das últimas entrevistas que concedeu no final da vida-foi um 


\section{artista múltiplo, importante para o teatro produzido nos dois lados do} oceano.

\section{REFERÊNCIAS BIBLIOGRÁFICAS}

ВАво, Alexandre (1993), Recordações de um caminheiro, Lisboa, Editorial Escritor.

BARATA, José Oliveira (2009), Máscaras da utopia: história do teatro universitário em Portugal 1938-1974, Lisboa, Fundação Calouste Gulbenkian.

TEUC (1969), «Carta aberta», 27 de Junho, Doc. MNTD - Espólio José de Oliveira Barata, pp. 1-3.

FARIA, Almeida (1969), «Texto de Apresentação», TEUC, Doc. MNTD - Espólio José de Oliveira Barata, pp. 1-3. GIL, Carlos (1969), «Um tema em equação: actualidade e actualização dos textos clássicos», A Capital, 24 de abril, pp. 4-5.

JACIN To, Denis (1959), «Ionesco no Teatro São João do Porto», in Vértice: Revista de Cultura e Arte, v. XIX, n. ${ }^{\circ} 190-$ -191 , julho/agosto, pp. 451-453.

LIMA, Luís de (1967), «Actualização estética e respeito pelos textos caracterizam Mestre Gil», in Diário de Lisboa, 13 de abril, pp. 13 e 15.

- (1969), «A peça: sua encenação», TEUC, Doc. MNTD - Espólio José de Oliveira Barata.

- (2003) Entrevista, in Fernando Lemos e Rui Moreira Leite (org.), A missão portuguesa: rotas entrecruzadas, São Paulo, UNESP/Scielo Books, pp. 1-57.

Lima, Luís de e MAscarenhas, Domingos (1967), Mestre Gil, Arquivo Nacional da Torre do Tombo (PT/TT/SNI-DGE/1/8404).

MAG ALDI, Sábato (2003), Depois do espetáculo, São Paulo, Perspectiva.

PIN TO, José Tavares (1969), «CITAC - XI Ciclo de Teatro: A ilha dos escravos, pelo TEUC», in Vértice: Revista de Cultura e Arte, maio, v. XXIX, n. ${ }^{\circ} 308$, pp. 404-406.

PORTo, Carlos (1973), Em busca do teatro perdido, vol. 2, Lisboa, Plátano.

- (1997), O TEP e o teatro em Portugal: histórias e imagens, Porto, Fundação Engenheiro António de Almeida.

Programa de Mestre Gil (1967), dramaturgia de Luís de Lima e Domingos Mascarenhas, encenação de Luís de Lima, Cénico de Direito, Lisboa, Doc. MNTD - Espólio José Oliveira Barata.

RAMos, Artur (1968), «Luís de Lima, um português que falta ao teatro do seu país», in Seara Nova, n. ${ }^{\circ} 1468$, fevereiro, pp. 70-71.

SILVA, Armando Sérgio (1989), Uma oficina de atores: a escola de arte dramática de Alfredo Mesquita, São Paulo, EDUSP.

VAsconcelos, José Carlos de (1967), «Mestre Gil: um notável espectáculo pelo Cénico de Direito», Diário de Lisboa, 15 de Abril, pp. 5 e 8.

VILAÇA, Mário (1960), «I Ciclo de Teatro em Coimbra», in Vértice: Revista de Cultura e Arte, abril, vol. xx, n. ${ }^{\circ}$ 199, pp. 224-231.

\section{MÁRCIA REGINA RODRIGUES}

Autora de Absurdo e censura no teatro português: a produção dramatúrgica de Hélder Prista Monteiro (2017), desenvolve actualmente pesquisa de pós-doutoramento no Departamento de Artes Cénicas da Escola de Comunicações e Artes da Universidade de São Paulo, sobre a trajectória de Luís de Lima no teatro brasileiro e português. 